\title{
Editorial \\ From 2009 to 2019: what a change!
}

\section{Peter M Suter}

Centre Médical Universitaire, University of Geneva, CH-1211 Genève 4, Switzerland

Corresponding author: Peter M Suter, peter.suter@unige.ch

Published: 1 June 2009

This article is online at http://ccforum.com/content/13/3/153

(C) 2009 BioMed Central Ltd
Critical Care 2009, 13:153 (doi:10.1186/cc7895)
May 2019 - The New York Times, the International Herald Tribune and the Frankfurter Allgemeine, based on a large survey conducted in the US, Canada, Europe, Australia and China, have concluded that the intensive care unit (ICU) is the most appealing workplace in the world.

Financial institutions and the stock exchange had been ranking highest in these regular international surveys until 2008 , when they dropped abruptly to the 167th position and were replaced at the top by the workplaces of information technicians, software developers and airline pilots. Professions in health care have been on a steady rise since 2012, reaching top positions in 2015 . Schools of medicine, nursing, public health and of other health care professions increased their enrolments by $120 \%$ between 2009 and 2015. At the same time, health care systems underwent dramatic improvements in all regions of the world. Not only have professionals in this field gained in recognition, but their workplaces public hospitals, policlinics and doctors' offices - now resemble modern airports or museums of modern art or the Chancellor's Office in Berlin.

These days, waiting lists for nurses wanting to work in the ICU are long and the interest among medical students, residents and board-certified internists, anaesthetists and intensivists to get a post in this part of the hospital is great. Quite a change since 2009, when a significant number of ICU beds were closed in many places, often for prolonged periods, due to a chronic lack of personnel. Nonetheless, the ICUs continued to work smoothly due to the enthusiastic spirit and dedication of mostly the experienced staff and attendants, which kept the group active and the ambiance positive. Finally, was it the shortage of human resources or the ever-increasing administrative hassle, the economic pressure to decrease the cost of everything or the increasing refusal of younger RNs and residents to stay in this 'crazy place', ignoring their dreams and priorities in life, that initiated the radical changes? Not really.
In the first place, society has changed. Quite possibly it started in Switzerland, where first, the government was forced to abolish banking secrecy after too many scandals and too much financial turmoil and bankruptcy, and second, a popular vote on 17 May 2009 changed the constitution so that all Swiss would have guaranteed access to 'alternative medicine' in addition to classical, science-based medicine. Soon thereafter, a new party was created in Germany 'Health now, Mercedes much later' - and its candidates won a fifth of the seats in parliament that fall. In its first action, the new party called for spending at least $25 \%$ of the gross national product on public health, a measure that passed by a landslide in parliament. Similar movements emerged in Great Britain, Russia, China and the US. As in Germany and the US, increases in taxes on tobacco products, soft drinks, gasoline, large cars, big incomes and airline passengers (1 cent per kilogram of body weight per 1,000 miles) were introduced to increase revenue for health care. The positive effects were astonishing: new clinics could be built, salaries of health care workers were doubled, patients were happy and more small cars and airline tickets were sold to physicians and nurses than ever before.

Society, patients and their families have changed too - really taking care of their health and caring about quality of life and demanding that high-tech high-cost medicine be limited to cases that clearly make sense, not in hopeless situations, not at 85 .

ICUs were the first in the new system to develop the principle of 'quality of life above all - for patients and staff', giving the team the responsibility of organizing the service according to principles of sound patient care and quality of professional life, including flexible shifts, job-sharing and part-time employment. On the same floor as the ICU, a nursery, which also serves the families of the cardiology and emergency department staffs, makes it possible for young mothers and fathers to feel close to their children during the day. Many tasks have

$\mathrm{ICU}=$ intensive care unit. 
changed hands in recent years: administration is run by clerks and administrators, management of beds and transferrals by patient-flow managers. Other tasks remain the same: nurses nurse, monitor and provide care, doctors search for a diagnosis and apply therapies. Both groups of professionals are as dedicated to global and human care as their colleagues were 10 years ago, but with the satisfaction of having more time to practice that dedication. Even more importantly, the staff is happy to work in this setting for many many years because the new values and priorities of their generation are recognized: not too many hours on the job, enough time for family, friends and outdoor activities - a hike or a bike - and no Mercedes and no investments in stock markets, which were closed definitively last year, in 2018.

\section{Competing interests}

The author declares that he has no competing interests. 